\title{
Non-parametric stability analyses of dough properties in wheat
}

\author{
Yuksel KAYA ${ }^{1 *}$, Mehmet SAHIN ${ }^{1}$
}

\begin{abstract}
Literature has unveiled that a paper has not been published yet on using non-parametric stability statistics (NPSSs) for evaluating genotypic stability in dough properties of wheat. Accordingly, the effects of genotype (G), environment (E) and GE interaction (GEI) on alveograph parameters, i.e. dough baking strength (W) and its tenacity (P)/extensibility (L), of 18 wheat (T. aestivum L.) genotypes were studied under irrigated field conditions in an 8-year trial (2006-2014) in central Turkey. Furthermore, genotypic stability for W and P/L was determined using 8 NPSSs viz. RM-Rank mean, RSD-Rank's standard deviation, RS-Rank Sum, TOP-Ranking, $S_{i}^{(1)}, S_{i}^{(2)}, S_{i}^{(3)}$ and $S_{i}^{(6)}$ rank statistics. The ANOVA revealed that W and P/L were primarily controlled by E, although G and GEI also had significant effects. Among the 8 NPSSs, only RM, RS and TOP statistics were suitable for detecting the genotypes with high stable and bread making quality (e.g. G1 and G17). In conclusion, using RM, RS and TOP statistics is advisable to select for dough quality in wheat under multi-environment trials (METs).
\end{abstract}

Keywords: alveograph; dough; stability; wheat.

Practical Application: Use of stability parameters for dough rheological features.

\section{Introduction}

As rheological characteristics of wheat dough are generally more reproducible among laboratories, and relate fairly well to end-use functionality, most of the world's wheat of commerce is traded based upon farinograph, extensigraph and alveograph values rather than to the results of baking test (Duyvejonck et al., 2012; Ferrari et al., 2014). In the case of alveograph (Chopin Technologies, 2000), dough baking strength $(\mathrm{W})$, tenacity $(\mathrm{P})$, extensibility $(\mathrm{L})$, and the balance between them $(\mathrm{P} / \mathrm{L})$ are very important for assessing dough rheological properties (Indrani et al., 2007; Codină et al., 2012; Li et al., 2013).

Achieving the demanded standards of dough rheological properties is complex as it is usually influenced by the genotype $(G)$, the environment $(E)$ and the complex interaction of genetic and environmental factors (GEI). The understanding of these effects is essential to help breeders to set proper objectives and strategies to develop wheat genotypes with high yield potential as well as with specific and consistent quality attributes to meet market needs The importance of the effects of G, E and GEI is increasing for breeders, growers, grain traders and end-use processors (Peterson et al., 1998; Souza et al., 2004; Williams et al., 2008).

In addition to the genotypic mean for any trait, the breeder is also interested in its stability, which depends on GEIs. Therefore, an assessment of stability in wheat could permit better genotype characterization (Robert, 2002).

Several stability statistics have been proposed to investigate G, E and GEI effects occurring in METs. They display different aspects of the stability approach, including parametric (e.g. slope of regression on an environmental index), non-parametric (e.g. rank-sum) and multi-variate methods (e.g. additive main effects and multiplicative interaction analysis) (Lin et al., 1986; Kang, 1988; Zobel et al., 1988). In this study, we were interested in using non-parametric stability statistics (NPSSs) in order to measure stabilities of wheat genotypes for dough properties (i.e. $\mathrm{W}$ and $\mathrm{P} / \mathrm{L}$ ). Because NPSSs do not depend on any assumptions about the distribution of phenotypic observations (Huehn, 1996) one can easily estimate the variance or standard deviation of the ranks of a genotype in different environments (Becker \& Leon, 1988).

In principal, NPSSs are based on the ranks of genotypes in each environment and genotypes with similar ranking across environments are classified as stable (Becker \& Leon, 1988). There are several NPSSs. For instance, Huehn (1996) proposed four nonparametric measures of stability $S_{i}^{(1)}, S_{i}^{(2)} S_{i}^{(3)}$ and $S_{i}{ }^{(6)}$. Ketata (1988) suggested rank mean (RM) against standard deviation of ranks (RSD). Fox et al. (1990) recommended a nonparametric superiority measure (TOP) for general adaptability. The Rank-Sum (RS) statistic was generated by Kang (1988).

According to the literature, no paper has been published yet in the context of our study. Therefore, we used the aforementioned NPSSs for detecting G, E and GEI effects on alveograph dough properties (i.e. $\mathrm{W}$ and $\mathrm{P} / \mathrm{L}$ ) of eighteen wheat genotypes tested across eight years (i.e. environments) in central Turkey.

The objectives of this study were (i) to identify wheat genotypes with high dough quality and stability tested across irrigated environments of Turkey and (ii) to determine the NPSSs suitable for detecting the genotypes with high dough quality and stable. 


\section{Materials and methods}

\subsection{Field trials}

A total of 18 genotypes of wheat (T. aestivum L.), composed of 2 breeding lines and 16 registered cultivars from Russia, Bulgaria, Ukraine and National Wheat Breeding Program of Turkey (NWBPT), and International Winter Wheat Improvement Program (International Winter Wheat Improvement Program, 2015), were grown in replicated trials in Konya, central Turkey, $\left(37^{\circ} 52^{\prime} \mathrm{N}, 32^{\circ} 29^{\prime} \mathrm{E}, 1016 \mathrm{~m}\right.$ above sea level), on a hydromorphic alluvial under the conditions of Mediterranean climate, during the 8 consecutive cropping seasons (from 2006 to 2014) (Tables 1 and 2). Field trials designed in completely randomized blocks with four replicates were sown in October and harvested in July each year. Sowing was done with an experimental drill in $1.2 \mathrm{~m} \times 7 \mathrm{~m}$ plots, consisting of 6 rows spaced $20 \mathrm{~cm}$ apart. The seeding rate was 450 seeds $\mathrm{m}^{-2}$. Fertilizer application was $27 \mathrm{~kg} \mathrm{~N} \mathrm{ha}^{-1}$ and $69 \mathrm{~kg} \mathrm{P}_{2} \mathrm{O}_{5} \mathrm{ha}^{-1}$ at the planting, $70 \mathrm{~kg} \mathrm{~N} \mathrm{ha}^{-1}$ at the stem elongation and $30 \mathrm{~kg} \mathrm{~N} \mathrm{ha}^{-1}$ at the grain filling stages. Harvesting was done with an experimental combine in $1.2 \mathrm{~m} \times 5 \mathrm{~m}$ plots.

Field trials received an annual precipitation between $230 \mathrm{~mm}$ and $325 \mathrm{~mm}$, with long term average of $289 \mathrm{~mm}$ (Table 2). In addition, a supplementary irrigation of $100 \mathrm{~mm}$ in total (i.e. $50 \mathrm{~mm}$ at stem elongation and $50 \mathrm{~mm}$ at grain filling stages) was applied to the genotypes studied for each cropping season.

\subsection{Milling}

Hard, medium-hard and soft wheat grain samples were tempered to around $16 \%, 15 \%$ and $14 \%$ moisture content, respectively. All samples were milled by using a Brabender Senior mill (Li et al., 2013).

\subsection{Dough test}

Dough properties for each genotype were determined by a Chopin MA 82 alveograph using AACC 54-30A method (American Association of Cereal Chemists, 2000). Each alveograph curve (Chopin Technologies, 2000) was analyzed with respect to four parameters: $\mathrm{P}$ - dough tenacity (aptitude to resist deformation), $\mathrm{L}$ - dough extensibility (maximum volume of air that the bubble is able to contain), $\mathrm{P} / \mathrm{L}$ - configuration of the curve and $\mathrm{W}-$ dough baking strength (surface under the curve) (Bordes et al., 2008; Hadnađev et al., 2011).

\subsection{Statistical analysis}

Annual data of dough properties (i.e. $\mathrm{W}$ and $\mathrm{P} / \mathrm{L}$ ) over the total 8-yr period were subjected to combined analysis of variance (ANOVA) (Table 3). Each year was considered as an individual environment in ANOVA.

NPSSs were done using SAS codes proposed by Hussein et al. (2000) for $\mathrm{S}_{i}^{(3)}$ and $\mathrm{S}_{i}^{(6)}$ (Huehn, 1996), RS (Kang, 1988), and TOP (Fox et al., 1990) and by Lu (1995) for $S_{i}^{(1)}$ and $S_{i}^{(2)}$ (Huehn, 1996). The other NPSSs, RM and RSD (Ketata, 1988) were estimated using Excel@.

\section{Results}

\subsection{Weather conditions}

As it is typical of the Mediterranean climate, quantity and distribution of precipitation were highly variable, but concentrated over the period between the end of autumn and the beginning of spring. Within 8 years of period stated earlier, precipitation (October-July) was varied from 230 to $325 \mathrm{~mm}$ (Table 2). Except for the 2010-2011 cropping season, all were characterized by a

Table 1. Code, origin, year of release, means of dough baking strength (W) and tenacity (P)/extensibility (L) for each genotype.

\begin{tabular}{|c|c|c|c|c|c|}
\hline Code & Genotype & Origin $\dagger$ & Year of release & $\mathrm{W}^{\ddagger}$ & $\mathrm{P} / \mathrm{L}$ \\
\hline G1 & 08-09 SEBVD-10 & Turkey & Breeding Line & 217 & 0.91 \\
\hline $\mathrm{G} 2$ & Ahmetaga & Turkey & 2005 & 228 & 0.72 \\
\hline G3 & Bagci-2002 & IWWIP & 2002 & 153 & 0.56 \\
\hline G4 & BDME 02-01-S & Turkey & Breeding Line & 213 & 0.84 \\
\hline G5 & Bezostaya-1 & Russia & 1959 & 202 & 0.82 \\
\hline G6 & Demir-2000 & Turkey & 2000 & 137 & 0.62 \\
\hline G7 & Ekiz & IWWIP & 2004 & 100 & 0.71 \\
\hline G8 & Eser & Turkey & 2003 & 107 & 0.39 \\
\hline G9 & Goksu-99 & IWWIP & 1999 & 112 & 0.49 \\
\hline G10 & Gun-91 & IWWIP & 1991 & 163 & 0.72 \\
\hline G11 & Katya-1 & Bulgaria & 1982 & 168 & 0.42 \\
\hline G12 & Kinaci-97 & IWWIP & 1997 & 161 & 0.55 \\
\hline G13 & Konya-2002 & Turkey & 2002 & 168 & 0.87 \\
\hline G14 & Pehlivan & Turkey & 1998 & 118 & 0.61 \\
\hline G15 & Sonmez-2001 & IWWIP & 2001 & 171 & 0.54 \\
\hline G16 & Sultan-95 & IWWIP & 1995 & 127 & 0.41 \\
\hline G17 & Tosunbey & Turkey & 2004 & 251 & 0.74 \\
\hline \multirow[t]{2}{*}{ G18 } & Krasunya-Odesskaya & Ukraine & 1997 & 237 & 0.58 \\
\hline & Mean & & & 169 & 0.64 \\
\hline
\end{tabular}

${ }_{\dagger}^{\dagger}$ IWWIP-International Winter Wheat Improvement Program (International Winter Wheat Improvement Program, 2015). ${ }^{\star} \mathrm{W}$-Dough baking strength $\left(\times 10^{-4} \mathrm{~J}\right)$, $\mathrm{P} / \mathrm{L}$-tenacity $(\mathrm{P}) /$ extensibility $(\mathrm{L})$. 
Table 2. Code, amounts of precipitation and irrigation, means of dough baking strength (W) and tenacity (P)/extensibility (L) for each environment.

\begin{tabular}{|c|c|c|c|c|c|c|}
\hline Code & Environment & Soil characteristics & Precipitation $(\mathrm{mm})$ & Irrigation $^{\dagger}(\mathrm{mm})$ & $\mathrm{W}^{\ddagger}$ & $\mathrm{P} / \mathrm{L}$ \\
\hline E1 & $2006-2007$ & $\mathrm{pH}=8.3$, hydromorphic alluvial & 230 & $50+50=100$ & 186 & 0.63 \\
\hline E2 & $2007-2008$ & $\mathrm{pH}=8.1$, hydromorphic alluvial & 274 & $50+50=100$ & 172 & 0.52 \\
\hline E3 & 2008-2009 & $\mathrm{pH}=8.4$, hydromorphic alluvial & 232 & $50+50=100$ & 189 & 0.61 \\
\hline E4 & $2009-2010$ & $\mathrm{pH}=8.0$, hydromorphic alluvial & 267 & $50+50=100$ & 154 & 0.53 \\
\hline E5 & $2010-2011$ & $\mathrm{pH}=8.2$, hydromorphic alluvial & 325 & $50+50=100$ & 171 & 0.80 \\
\hline E6 & 2011-2012 & $\mathrm{pH}=8.3$, hydromorphic alluvial & 258 & $50+50=100$ & 156 & 0.78 \\
\hline E7 & $2012-2013$ & $\mathrm{pH}=8.1$, hydromorphic alluvial & 233 & $50+50=100$ & 169 & 0.70 \\
\hline \multirow[t]{2}{*}{ E8 } & 2013-2014 & $\mathrm{pH}=8.2$, hydromorphic alluvial & 235 & $50+50=100$ & 152 & 0.74 \\
\hline & Mean & & 289 & & 169 & 0.64 \\
\hline
\end{tabular}

${ }^{\dagger}$ Irrigation was made as $50 \mathrm{~mm}$ at stem elongation and $50 \mathrm{~mm}$ grain filing stages, respectively. ${ }^{\star} \mathrm{W}$-Dough baking strength $\left(\times 10^{-4} \mathrm{~J}\right), \mathrm{P} / \mathrm{L}-$ tenacity $(\mathrm{P}) / \mathrm{extensibility}(\mathrm{L})$.

Table 3. Combined analyses of variance (ANOVA) for dough baking strength (W) and tenacity (P)/extensibility (L).

\begin{tabular}{|c|c|c|c|c|c|c|c|}
\hline \multirow{2}{*}{ Source } & \multirow{2}{*}{$\mathrm{df}$} & $\mathrm{W}$ & \multirow{2}{*}{ MS } & \multirow{2}{*}{$(\%)$} & $\mathrm{P} / \mathrm{L}$ & \multirow{2}{*}{ MS } & \multirow{2}{*}{$(\%)$} \\
\hline & & SS & & & SS & & \\
\hline Environment(E) & 7 & $698,786.54$ & $99,826.65^{\star \star}$ & 58.1 & 12.34 & $1.76^{\star *}$ & 55.6 \\
\hline Replication (E) & 24 & $50,124.79$ & $2,088.53$ & & 0.87 & 0.04 & \\
\hline Genotype (G) & 17 & $299,876.23$ & $17,639.78^{\star *}$ & 24.9 & 5.88 & $0.35^{\star *}$ & 26.5 \\
\hline $\mathrm{G} \times \mathrm{E}$ Interaction & 119 & $203,457.64$ & $1,709.73^{\star *}$ & 16.9 & 3.98 & $0.03^{* *}$ & 17.9 \\
\hline Error & 408 & $49,089.45$ & 120.32 & & 0.69 & 0.01 & \\
\hline Total & 575 & $1,301,334.65$ & & 100.0 & 23.76 & & 100.0 \\
\hline $\mathrm{CV}_{(\%)}$ & & 4.51 & & & 5.41 & & \\
\hline Mean & & $169 \times 10^{-4} \mathrm{~J}$ & & & 0.64 & & \\
\hline
\end{tabular}

**Significant at the 0.01 probability level.

long drought stress period affecting all the main developmental phases with probably more intense water stress during grain filling, while high temperatures occurred concomitantly with low precipitation. It is likely that the drought occurrence altered the efficiency of supplementary irrigation treatments on field trials. However, this kind of alteration could not be of importance for dough features evaluated in this study, since correlations of annual precipitation amounts across environments with $\mathrm{W}$ and $\mathrm{P} / \mathrm{L}$ values were not significant $\left(\mathrm{r}=-0.175^{\mathrm{NS}}, \mathrm{r}=0.215^{\mathrm{NS}}\right.$, respectively).

\subsection{ANOVA and mean comparisons}

Table 3 summarized the ANOVA results of G, E and GEI for dough features (i.e. $\mathrm{W}$ and $\mathrm{P} / \mathrm{L}$ ) evaluated in the study. Considering the variance sources, both $\mathrm{W}$ and $\mathrm{P} / \mathrm{L}$ were statistically significant $(\mathrm{P}<0.01)$.

Relative contributions of $\mathrm{G}$ and $\mathrm{E}$ to the total variation were assessed as the percentage of total sum of squares (Table 3 ). Both $\mathrm{W}$ and $\mathrm{P} / \mathrm{L}$ were sensitive to GEIs. Also, genetic variation was considerably lower for $\mathrm{W}$ and $\mathrm{P} / \mathrm{L}$, while environmental variation contributed higher to them.

The alveograph characteristics of genotypes showed that $\mathrm{W}$ representing the energy necessary to inflate the dough bubble to the point of rupture ranged from $100 \times 10^{-4} \mathrm{~J}$ for G7 to $251 \times 10^{-4} \mathrm{~J}$ for G17, with mean of $169 \times 10^{-4} \mathrm{~J}$ (Table 1 ). On the other hand, the values for curve configuration ratio, $\mathrm{P} / \mathrm{L}$, indicating the ratio of tenacity $(\mathrm{P})$ to extensibility $(\mathrm{L})$ of the dough varied between 0.39 for G8 and 0.91 for G1. As for dough characteristics obtained from the environments, W ranged from $152 \times 10^{-4} \mathrm{~J}$ for E8 to $189 \times 10^{-4} \mathrm{~J}$ for $\mathrm{E} 3$ and $\mathrm{P} / \mathrm{L}$ varied from 0.52 for $\mathrm{E} 2$ to 0.80 for E5 (Table 2). It was found that genotype variations for $\mathrm{W}$ and $\mathrm{P} / \mathrm{L}$ were wider than those of the environments.

\subsection{Nonparametric stability statistics for dough baking strength $(W)$}

Assessment of the 18 genotypes based on the 8 NPSSs, together with W means, is presented in Table 4. Ketata (1988) proposed two non-parametric methods: rank's mean (RM) and its standard deviation (RSD). According to RM, genotypes G1, G2, G4, G5, G17 and G18 were the most desirable, because they had lower RM values, whereas genotypes G5, G6, G11, G14, G17 and G18 were the most desirable for RSD (Tables 4). Among them G5, G17 and G18 were the most stable for both NPSSs and also their $W$ values were higher than that of mean genotype $\left(169 \times 10^{-4} \mathrm{~J}\right)$ (Table 4$)$.

Kang's (1988) rank-sum (RS) statistic uses both W mean and stability variance. The genotypes with the lowest RS are the most favorable ones. According to the RS statistic, G1, G2, G5 G17 and G18 had the lowest values for RS and therefore were the most stable ones (Table 4).

The nonparametric measure of Fox et al. (1990) consists of scoring the percentage of environments in which each genotype ranked in the top (TOP), middle (MID) and bottom (BOT) third of trial entries. A genotype usually found in the top third 
of entries across environments can be considered relatively well adapted and stable. Thus, G17 and G18 were well adapted genotypes, because they ranked in the top third of genotypes in a highest percentage of environments (TOP $=100 \%)$, and were followed by G1, G2, G4 and G5 (TOP > 62.5\%) (Table 4).

According to the significance tests for $\mathrm{S}_{\mathrm{i}}^{(1)}$ and $\mathrm{S}_{\mathrm{i}}^{(2)}$ developed by Huehn (1996), there were no significant differences in rank stability among the genotypes (except G7 and G13) grown in 8 environments (Table 4). G7 and G13, however, were significantly unstable in compare to others. Genotypes with fewer changes in rank are considered to be more stable. The $S_{i}^{(1)}$ estimates are based on all possible pair-wise rank differences across environments for each genotype, whereas $S_{i}^{(2)}$ is based on variances of ranks for each genotype across environments (Huehn, 1996). These two statistics are ranked of genotypes similarity for stability. For example, according to both $S_{i}^{(1)}$ and $S_{i}^{(2)}, G 1, G 5, G 6$ and G14 had the smallest changes in ranks and therefore, are regarded as the most stable genotypes. However, among the most stable genotypes, G6 and G14 had lower W than that of the average genotype $\left(169 \times 10^{-4} \mathrm{~J}\right)$ (Table 4$)$.

Two other nonparametric statistics of Huehn (1996), $S_{i}^{(3)}$ and $\mathrm{S}_{i}{ }^{(6)}$ combine $\mathrm{W}$ and stability based on $\mathrm{W}$ ranks of genotypes in each environment. These parameters measure stability in units of the mean rank of each genotype. The lowest value for each of these statistics indicates maximum stability for a certain genotype. G6, G11 and G14 were the most stable ones according to the $\mathrm{S}_{\mathrm{i}}^{(3)}$ and $\mathrm{S}_{\mathrm{i}}^{(6)}$ parameters. On the other hand, their $\mathrm{W}$ values were lower than that of the mean genotype (Table 4).

In the context of this study, we were interested in determining the stable genotypes with high W using the NPSSs. Considering
8 NPSSs, only RM, RS and TOP were able to detect the genotypes with higher stability and W value. Consequently, G1, G5, G17 and G18 were determined to be suitable for the objectives of this study.

\subsection{Nonparametric stability statistics for dough tenacity $(P) /$ extensibility $(L)$}

Evaluation of genotype stability for P/L using 8 NPSSs is shown in Table 5. With respect to RM, G1, G4, G5, G14 and G17 were the most stable, while G4, G8, G14 and G17 were the most desirable for RSD. Among them G4, G14 and G17 were the most stable for both NPSSs. As for RS, G1, G4, G14 and G17 had the lowest values and therefore were the most stable ones (Table 5). On the other hand, G1 was the most adapted and stable genotype, since it ranked in the top over genotypes tested in the study (TOP $=100 \%)$. G4, G13 and G14 were also among the most stable ones (TOP $>75 \%$ ) (Table 5).

Regarding the significance tests for $\mathrm{S}_{\mathrm{i}}^{(1)}$ and $\mathrm{S}_{\mathrm{i}}^{(2)}$, solely $\mathrm{G} 6$ and G13 were significantly different from the other genotypes tested (Table 5). Based on both $S_{i}^{(1)}$ and $S_{i}^{(2)}, G 1, G 2, G 8$ and G17 were regarded as the most stable genotypes. However, among the most stable ones, G2 and G8 had lower P/L than the mean genotype had (0.64) (Table 5). On the other hand G2, G8 and G16 were the most stable genotypes according to the $S_{i}^{(3)}$ and $S_{i}^{(6)}$ parameters. But, their $\mathrm{P} / \mathrm{L}$ values were lower than that of the mean genotype (Table 5). Taking into account of all NPSSs, the G1, G4 and G17 were identified as desirable genotypes, with higher stable and $\mathrm{P} / \mathrm{L}$ close to optimum value of 1.0 (Bordes et al., 2008). In conclusion, G1 and G17 were the most desirable genotypes for both $\mathrm{W}$ and $\mathrm{P} / \mathrm{L}$ values.

Table 4. Non-parametric stability statistics for dough baking strength (W).

\begin{tabular}{|c|c|c|c|c|c|c|c|c|c|c|}
\hline Code & Genotype & $\mathrm{W}^{\dagger}$ & $\mathrm{RM}$ & RSD & RS & TOP & $\mathrm{S}_{\mathrm{i}}^{(1)}$ & $\mathrm{S}_{\mathrm{i}}^{(2)}$ & $\mathrm{S}_{\mathrm{i}}^{(3)}$ & $\mathrm{S}_{\mathrm{i}}^{(6)}$ \\
\hline G1 & 08-09 SEBVD-10 & 217 & 4 & 2.0 & 8 & 75.0 & 3.2 & 9.5 & 3.6 & 2.5 \\
\hline $\mathrm{G} 2$ & Ahmetaga & 228 & 4 & 2.2 & 10 & 75.0 & 4.5 & 15.2 & 6.9 & 3.6 \\
\hline G3 & Bagci & 153 & 10 & 3.2 & 23 & 12.5 & 5.1 & 18.2 & 5.1 & 2.1 \\
\hline G4 & BDME 02-01-S & 213 & 5 & 2.6 & 18 & 75.0 & 5.2 & 20.1 & 8.6 & 3.6 \\
\hline G5 & Bezostaya-1 & 202 & 6 & 1.8 & 11 & 62.5 & 3.3 & 9.9 & 2.9 & 1.9 \\
\hline G6 & Demir-2000 & 137 & 12 & 1.6 & 14 & 0.0 & 3.0 & 8.2 & 1.1 & 0.7 \\
\hline G7 & Ekiz & 100 & 15 & 2.8 & 28 & 0.0 & $6.1^{*}$ & $22.1^{\star}$ & 1.6 & 1.1 \\
\hline G8 & Eser & 107 & 14 & 3.3 & 30 & 0.0 & 5.2 & 17.2 & 3.4 & 1.5 \\
\hline G9 & Goksu-99 & 112 & 14 & 2.9 & 25 & 0.0 & 4.1 & 14.5 & 2.0 & 1.1 \\
\hline G10 & Gun-91 & 163 & 9 & 4.1 & 26 & 12.5 & 4.7 & 16.2 & 8.2 & 2.1 \\
\hline G11 & Katya-1 & 168 & 17 & 0.8 & 21 & 0.0 & 3.8 & 12.3 & 0.2 & 0.3 \\
\hline G12 & Kinaci-97 & 161 & 10 & 2.4 & 19 & 12.5 & 5.0 & 12.2 & 1.8 & 1.5 \\
\hline G13 & Konya-2002 & 168 & 10 & 4.1 & 26 & 37.5 & $6.4^{*}$ & $25.2^{*}$ & 9.2 & 2.8 \\
\hline G14 & Pehlivan & 118 & 14 & 1.5 & 15 & 0.0 & 0.8 & 5.7 & 0.5 & 0.7 \\
\hline G15 & Sonmez-2001 & 171 & 9 & 3.7 & 22 & 25.0 & 4.7 & 11.2 & 6.2 & 2.3 \\
\hline G16 & Sultan-95 & 127 & 13 & 4.2 & 29 & 12.5 & 5.8 & 10.2 & 5.6 & 2.1 \\
\hline G17 & Tosunbey & 251 & 2 & 1.5 & 9 & 100.0 & 3.5 & 11.2 & 5.1 & 4.3 \\
\hline \multirow[t]{2}{*}{ G18 } & Krasunya-Odesskaya & 237 & 3 & 1.7 & 8 & 100.0 & 4.0 & 12.1 & 4.6 & 3.4 \\
\hline & Mean & 169 & 10 & 2.6 & 19.0 & 33.3 & 4.3 & 14.0 & 4.3 & 2.1 \\
\hline
\end{tabular}

*Significant at the 0.05 probability level. ${ }^{\dagger}$ Symbols: W-Dough baking strength $\left(\times 10^{-4} \mathrm{~J}\right)$, RM-Rank mean, RSD-Rank's standard deviation (Ketata, 1988), RS-Rank Sum stability statistic (Kang, 1988), TOP-Proportion of environments in which a genotype ranked in the top third (Fox et al. 1990), $\mathrm{S}_{i}^{(1)}, \mathrm{S}_{i}^{(2)}, \mathrm{S}_{i}^{(3)}$ and $\mathrm{S}_{i}^{(6)}$-Ranks of adjusted W means of genotypes (Huehn, 1996). 
Table 5. Non-parametric stability statistics for dough tenacity (P)/extensibility (L).

\begin{tabular}{|c|c|c|c|c|c|c|c|c|c|c|}
\hline Code & Genotype & $\mathrm{P} / \mathrm{L}^{\dagger}$ & $\mathrm{RM}$ & RSD & RS & TOP & $S_{i}^{(1)}$ & $\mathrm{S}_{i}^{(2)}$ & $S_{i}^{(3)}$ & $S_{i}^{(6)}$ \\
\hline G1 & 08-09 SEBVD-10 & 0.91 & 5 & 2.4 & 4 & 100.0 & 2.6 & 5.4 & 3.8 & 3.5 \\
\hline $\mathrm{G} 2$ & Ahmetaga & 0.72 & 12 & 2.3 & 16 & 0.0 & 1.7 & 2.2 & 1.2 & 0.9 \\
\hline G3 & Bagci & 0.56 & 12 & 5.2 & 16 & 12.5 & 3.1 & 10 & 5.5 & 1.9 \\
\hline G4 & BDME 02-01-S & 0.84 & 4 & 1.8 & 14 & 75.0 & 5.2 & 18.2 & 5.4 & 2.9 \\
\hline G5 & Bezostaya-1 & 0.82 & 6 & 4.5 & 19 & 50.0 & 5.7 & 25.1 & 8.2 & 4.1 \\
\hline G6 & Demir-2000 & 0.62 & 11 & 5.0 & 20 & 50.0 & $6.5^{\star}$ & $31.3^{*}$ & 16.2 & 4.8 \\
\hline G7 & Ekiz & 0.71 & 7 & 3.7 & 19 & 25.0 & 4.1 & 10.2 & 5.4 & 2.2 \\
\hline G8 & Eser & 0.39 & 16 & 1.6 & 19 & 0.0 & 1.6 & 2.3 & 1.1 & 0.6 \\
\hline G9 & Goksu-99 & 0.49 & 13 & 3.7 & 22 & 0.0 & 3.4 & 9.8 & 5.1 & 1.7 \\
\hline G10 & Gun-91 & 0.72 & 8 & 3.3 & 24 & 50.0 & 5.1 & 20.4 & 9.1 & 3.3 \\
\hline G11 & Katya-1 & 0.42 & 13 & 4.9 & 30 & 0.0 & 4.3 & 13.2 & 5.4 & 2.1 \\
\hline G12 & Kinaci-97 & 0.55 & 11 & 5.3 & 27 & 25.0 & 5.1 & 21.1 & 11.2 & 3.1 \\
\hline G13 & Konya-2002 & 0.87 & 8 & 6.5 & 21 & 75.0 & $6.9^{*}$ & $34.8^{\star}$ & 18.3 & 5.9 \\
\hline G14 & Pehlivan & 0.61 & 6 & 1.7 & 14 & 75.0 & 4.5 & 16.2 & 4.6 & 3.0 \\
\hline G15 & Sonmez-2001 & 0.54 & 10 & 6.1 & 21 & 12.5 & 4.1 & 12.4 & 8.7 & 2.8 \\
\hline G16 & Sultan-95 & 0.41 & 15 & 2.5 & 29 & 0.0 & 4.9 & 21.5 & 1.6 & 1.1 \\
\hline G17 & Tosunbey & 0.74 & 5 & 1.7 & 11 & 50.0 & 2.5 & 4.5 & 2.3 & 2.1 \\
\hline \multirow[t]{2}{*}{ G18 } & Krasunya-Odesskaya & 0.58 & 11 & 4.7 & 16 & 0.0 & 3.9 & 9.9 & 4.7 & 2.0 \\
\hline & Mean & 0.64 & 10 & 3.7 & 19.0 & 33.3 & 4.0 & 14.9 & 6.5 & 2.7 \\
\hline
\end{tabular}

${ }^{\star}$ Significant at the 0.05 probability level. `Symbols: P/L-Dough tenacity (P)/extensibility (L), RM-Rank mean, RSD-Rank's standard deviation (Ketata, 1988), RS-Rank Sum stability statistic (Kang, 1988), TOP-Proportion of environments in which a genotype ranked in the top third (Fox et al., 1990), $\mathrm{S}_{\mathrm{i}}^{(1)}, \mathrm{S}_{\mathrm{i}}^{(2)}, \mathrm{S}_{\mathrm{i}}^{(3)}$ and $\mathrm{S}_{\mathrm{i}}^{(6)}$-Ranks of adjusted P/L means of genotypes (Huehn, 1996).

\section{Discussion}

Wheat breeders are under perpetual pressure to improve not only, grain yield, but also the industrial milling and baking quality of the grain. The use of alveograph parameters to help truncate populations in the early generations allows breeders to reduce the number of genotypes entering yield testing and favorably increase of the frequency of lines with good grain quality (Trethowan et al., 2001).

According to Mailhot \& Patton (1988) P and L of the dough are considered the most important characteristics in the bread-making quality. In general, strong flours are characterized by high $\mathrm{P}$ and $\mathrm{W}$ and low or medium L values (Dubois et al., 2008). Thus, Bordes et al. (2008) classified wheat genotypes on the basis of alveogram parameters. $\mathrm{P} / \mathrm{L}$ is commonly used in wheat trade where value of 0.50 indicates either resistant and very extensible dough or moderately extensible less resistant dough. Furthermore, value of 1.50 indicates very strong and moderately extensible dough, whilst raw material with $\mathrm{P} / \mathrm{L}$ value in the range $0.40-0.80$ is suitable for bakery production. Concerning the interpretation of $\mathrm{W}$ value for standard quality wheat is characterized by $\mathrm{W}$ value in range 160-200 $\times 10^{-4} \mathrm{~J}$, whilst good quality wheat and improving wheat are characterized by $\mathrm{W}$ value in the range $220-300 \times 10^{-4} \mathrm{~J}$ and higher than $300 \times 10^{-4} \mathrm{~J}$, respectively (Pagani et al., 2006; Bordes et al., 2008).

Regarding the wheat trade rules declared by Turkish Grain Board (Toprak Mahsulleri Ofisi Genel, 2014), dough properties of wheat for commerce may not be presented, due to the fact that their declaration is not compulsory yet. Furthermore dough features have not been yet accepted as obliged criteria for Turkish Wheat Classification. For this reason we could not classify the genotypes used in this study regarding dough properties. On the other hand, it is obvious that regardless of dough characteristics, classifying wheat may result in a handicap of high quality wheat to be imported by Turkey, since grain of 4.754 .682 tons was imported by Turkey in 2011 to meet the domestic demand for the high quality wheat (Food and Agriculture Organization Corporate Statistical Database, 2012).

According to the wheat cultivar registration procedure in Turkey, dough characteristics, including alveograph parameters, must be proved for comparing the newly developed cultivars with standard counterparts during the official registration trials (ORTs). However, there is no range of dough parameters to classify the newly developed cultivars in use of the evaluation process of registration. Although, ORTs are conducted in multi-environment (year $\times$ location combinations) trials (METs), quality analyses are still carried out on data coming from a single environment trial. Therefore, selection efficiency in quality traits would be lower than what we expected, because GEI effects on quality traits are significant (Vázquez et al., 2012; Costa et al., 2013).

The results of this study confirmed the most of the advanced breeding lines and registered cultivars in Turkey having medium quality for alveograph parameters (i.e. $\mathrm{W}$ and $\mathrm{P} / \mathrm{L}$ ). There are several reasons why they are inferior in quality. Firstly, only three out of twelve national research institutes dealing with wheat breeding in Turkey have the alveograph instrument to make dough analyses in their quality laboratories. Genotypes tested in various breeding trials could not be well screened for quality traits, especially for dough parameters, because of the lack of laboratory equipment. Secondly, breeding lines selected from IWWIP (International Winter Wheat Improvement Program, 2015) to NWBPT also were low in quality. This was 
not surprising to us, because increasing yield potential is still on the top of breeding priority list of IWWIP. Thirdly, in our breeding program, quality analyses are still being conducted in a single environment (or location or year) trials, but not in METs. Many studies clearly showed that quality traits are under the control of GEIs (Williams et al., 2008; Vázquez et al., 2012; Kaya \& Akcura 2014). In advance to genotype selection process in METs for high quality, genotype stability needs to be estimated by using various stability statistics as a preliminary step. On the other hand, it is possible to develop the genotypes with high stable and good bread making quality. For instance, G1 and G17, breeding line and registered cultivar originated from NWBPT respectively, were among the most desirable ones, with regard to their stabilities and dough features (i.e. $\mathrm{W}$ and $\mathrm{P} / \mathrm{L}$ ).

In this study, we used eight NPSSs, since they have certain advantages with respective to parametric ones (Becker \& Leon 1988; Huehn, 1996). Among them, only RM (Ketata, 1988), RS (Kang, 1988) and TOP (Fox et al., 1990) were determined to be suitable for detecting the genotypes with high stable and dough baking quality. Unfortunately, we could not find any paper published in literature in favor of (or against) our findings. Therefore, we did not discuss our findings in the light of previous literature for justification.

\section{Conclusions}

In this study, we found that GEI was significant for the alveograph parameters (e.g. W and P/L); therefore, the dough analyses should be run in METs. The conclusion for breeders is that if top quality wheat cannot be obtained, it could be due to environmental effects rather than deficiency of the genotype selection. Therefore, in wheat breeding, quality objectives should be set by considering both G, E and GEI effects (Vázquez et al., 2012). In addition, genotypic stability for the alveograph parameters can be determined using the NPSSs such as RM, RS and TOP.

\section{Acknowledgements}

This study was supported by the Ministry of Food, Agriculture and Livestock, Republic of Turkey, Project No: TAGEM/ TA/11/07/01/002.

\section{References}

American Association of Cereal Chemists - AACC. (2000). Approved methods of the American Association of Cereal Chemists (10th ed.). St. Paul: AACC.

Becker, H. C., \& Leon, J. (1988). Stability analysis in plant breeding. Plant Breeding, 101(1), 1-23. http://dx.doi.org/10.1111/j.1439-0523.1988. tb00261.x.

Bordes, J., Branlard, G., Oury, F. X., Charmet, G., \& Balfourier, F. (2008). Agronomic characteristics, grain quality and flour rheology of 372 bread wheats in a worldwide core collection. Journal of Cereal Science, 48(3), 569-579. http://dx.doi.org/10.1016/j.jcs.2008.05.005.

Chopin Technologies. (2000). Méthodes et équipements pour la maîtrise característiques des céréales et dérivés. Villeneuve-la-Garenne: Chopin. Retrieved from http://www.chopin.fr/fr

Codină, G. G., Mironeasa, S., Mironeasa, C., Popa, C. N., \& TambaBerehoiu, R. (2012). Wheat flour dough Alveograph characteristics predicted by Mixolab regression models. Journal of the Science of Food and Agriculture, 92(3), 638-644. http://dx.doi.org/10.1002/ jsfa.4623. PMid:21919003.

Costa, M. S., Scholz, M. B. S., \& Franco, C. M. L. (2013). Effect of high and low molecular weight glutenin subunits, and subunits of gliadin on physicochemical parameters of different wheat genotypes. Food Science and Technology, 33(Suppl. 1), 163-170. http://dx.doi. org/10.1590/S0101-20612013000500024.

Dubois, M., Dubat, A., \& Launay, B. (2008). The alveo consistograph handbook (2nd ed.). St. Paul: AACC International.

Duyvejonck, A. E., Lagrain, B., Dornez, E., Delcour, J. A., \& Courtin, C. M. (2012). Suitability of solvent retention capacity tests to assess the cookie and bread making quality of European wheat flours. LWT - Food Science and Technology, 47, 56-63.

Ferrari, M. C., Clerici, M. T. P. S., \& Chang, Y. K. (2014). A comparative study among methods used for wheat flour analysis and for measurements of gluten properties using the Wheat Gluten Quality Analyser (WGQA). LWT - Food Science and Technology, 34(2), 235242. http://dx.doi.org/10.1590/fst.2014.0038.

Food and Agriculture Organization Corporate Statistical Database FAOSTAT. (2012). Rome: FAO. Retrieved from http://faostat.fao.org/.

Fox, P. N., Skovmand, B., Thompson, B. K., Braun, H. J., \& Cormier, R. (1990). Yield and adaptation of hexaploid spring triticale. Euphytica, 47(1), 57-64. http://dx.doi.org/10.1007/BF00040364.

Hadnađev, T. D., Pojic, M., Hadnadev, M., \& Torbica, A. (2011). The Role of empirical rheology in flour quality control. In I. Akyar (Ed.), Wide spectra of quality control (pp. 335-360). Rijeka: InTech. Retrieved from http://www.intechopen.com/books/wide-spectra-of-qualitycontrol/the-role-of-empirical-rheology-in-flour-quality-control.

Huehn, M. (1996). Non-parametric analysis of genotype x environment interactions by ranks. In M. S. Kang \& H. G. Gauch Jr. (Eds.), Genotype by environment interaction (pp. 235-271). Boca Raton: CRC Press.

Hussein, M. A., Bjornstad, A., \& Aastveit, A. H. (2000). SASG x ESTAB: a SAS program for computing genotype $\mathrm{x}$ environment stability statistics. Agronomy Journal, 92(3), 454-459. http://dx.doi. org/10.2134/agronj2000.923454x.

Indrani, D., Manohar, R. S., Rajiv, J., \& Rao, G. V. (2007). Alveograph as a tool to assess the quality characteristics of wheat flour for parotta making. Journal of Food Engineering, 78(4), 1202-1206. http://dx.doi. org/10.1016/j.jfoodeng.2005.12.032.

International Winter Wheat Improvement Program - IWWIP. (2015). Ankara: IWWPI. Retrieved from http://www.iwwip.org/.

Kang, M. S. (1988). A rank-sum method for selecting high yielding, stable corn genotypes. Cereal Research Communications, 16, 113-115.

Kaya, Y., \& Akcura, M. (2014). Effects of genotype and environment on grain yield and quality traits in bread wheat (T. aestivum L.). Food Science and Technology, 34(2), 386-393. http://dx.doi.org/10.1590/ fst.2014.0041.

Ketata, H. (1988). Genotype × environment interaction. In Proceeding of the Workshop on Biometrical Techniques for Cereal Breeders. Aleppo, Syria.

Li, Y., Wu, Y., Hernandez-Espinosa, N., \& Peña, R. J. (2013). The influence of drought and heat stress on the expression of end use quality parameters of common wheat. Journal of Cereal Science, 57(1), 73-78. http://dx.doi.org/10.1016/j.jcs.2012.09.014.

Lin, C. S., Binns, M. R., \& Lefkovitch, L. P. (1986). Stability analysis: where do we stand? Crop Science, 26(5), 894-900. http://dx.doi. org/10.2135/cropsci1986.0011183X002600050012x. 
Lu, H. S. (1995). PC-SAS Program for estimating Huhn's nonparametric stability statistics. Agronomy Journal, 87(5), 888-891. http://dx.doi. org/10.2134/agronj1995.00021962008700050018x.

Mailhot, W. C., \& Patton, J. C. (1988). Criteria of flour quality. In Y. Pomeranz (Ed.), Wheat: chemistry and technology (Vol. II, pp. 6990). St. Paul: AACC.

Pagani, M. A., Lucisano, M., \& Mariotti, M. (2006). Italian bakery. In Y. H. Hui (Ed.), Bakery products quality and technology (pp. 527-560). Ames: Blackwell Publishing.

Peterson, C. J., Graybosch, R. A., Shelton, D. R., \& Baenziger, P. S. (1998). Baking quality of hard winter wheat: response of cultivars to environment in the Great Plains. Euphytica, 100(1-3), 157-162. http://dx.doi.org/10.1023/A:1018361502435.

Robert, N. (2002). Comparison of stability statistics for yield and quality traits in bread wheat. Euphytica, 128(3), 333-341. http:// dx.doi.org/10.1023/A:1021296919225.

Souza, E. J., Martin, J. M., Guttieri, M. J., O’brien, K. M., Habernicht, D. K., Lanning, S. P., Mclean, R., Carlson, G. R., \& Talbert, L. E. (2004). Influence of genotype, environment and nitrogen management on spring wheat quality. Crop Science, 44(2), 425-432. http://dx.doi. org/10.2135/cropsci2004.4250.
Toprak Mahsulleri Ofisi Genel Müdürlüğü - TMO. (2014). Ankara: TMO. Retrieved from http://www.tmo.gov.tr/Main.aspx?ID=1.

Trethowan, R. M., Pena, R. J., \& van Ginkel, M. (2001). The effect of indirect tests for grain quality on the grain yield and industrial quality of bread wheat. Plant Breeding, 120(6), 509-512. http:// dx.doi.org/10.1046/j.1439-0523.2001.00651.x.

Vázquez, D., Berger, A. G., Cuniberti, M., Bainotti, C., Miranda, M. Z., Scheeren, P. L., Jobet, C., Zuniga, J., Cabrera, G., Verges, R., \& Pena, R. J. (2012). Influence of cultivar and environment on quality of Latin American wheats. Journal of Cereal Science, 56(2), 196-203. http://dx.doi.org/10.1016/j.jcs.2012.03.004.

Williams, R. M., O’brien, L., Eagles, H. A., Solah, V. A., \& Jayasena, V. (2008). The influences of genotype, environment, and genotype $\times$ environment interaction on wheat quality. Australian Journal of Agricultural Research, 59(2), 95-111. http://dx.doi.org/10.1071/ AR07185.

Zobel, W. R., Wright, M. J., \& Gauch, H. G. (1988). Statistical analysis of a yield trial. Agronomy Journal, 80(3), 388-393. http://dx.doi. org/10.2134/agronj1988.00021962008000030002x. 